\title{
Structure and properties of $\operatorname{SmCu}_{6-x} \operatorname{In}_{6+x}(x=0,1,2)$
}

\author{
UDUMULA SUBBARAO and SEBASTIAN C PETER* \\ New Chemistry Unit, Jawaharlal Nehru Centre for Advanced Scientific Research, Jakkur, \\ Bangalore 560 064, India \\ e-mail: sebastiancp@jncasr.ac.in
}

MS received 29 January 2013; revised 14 June 2013; accepted 18 July 2013

\begin{abstract}
High quality single crystals of $\mathrm{SmCu}_{6} \mathrm{In}_{6}$ were obtained from the reactions run in excess liquid indium and characterized by means of single crystal X-ray diffraction data. $\mathrm{SmCu}_{6} \mathrm{In}_{6}$ crystallizes in the $\mathrm{YCu}_{6} \mathrm{In}_{6}$ structure type, tetragonal space group I4/mmm and lattice constants are $a=b=9.2036$ (3) $\AA$ and $c=5.4232(3) \AA . \mathrm{SmCu}_{6-\mathrm{x}} \operatorname{In}_{6+\mathrm{x}}(x=0,1,2)$ compounds were obtained using arc melting and characterized using powder X-ray diffraction. Magnetic susceptibility data follow modified Curie-Weiss law behaviour above $50 \mathrm{~K}$ and the experimentally measured magnetic moment values in $\mathrm{SmCu}_{4} \mathrm{In}_{8}, \mathrm{SmCu}_{5} \mathrm{In}_{7}$ and $\mathrm{SmCu}_{6} \mathrm{In}_{6}$ are $0.83 \mu_{\mathrm{B}}, 1.45 \mu_{\mathrm{B}}$ and $0.90 \mu_{\mathrm{B}}$ per $\mathrm{Sm}$ atom, respectively. $\mathrm{SmCu}_{5} \mathrm{In}_{7}$ and $\mathrm{SmCu}_{6} \mathrm{In}_{6}$ compounds show antiferromagnetic ordering at $T_{\mathrm{N}}=7.8 \mathrm{~K}$, and no magnetic ordering was observed for $\mathrm{SmCu}_{4} \mathrm{In}_{8}$ down to $2 \mathrm{~K}$. Electrical resistivity measurements show that all compounds are of metallic nature.
\end{abstract}

Keywords. Rare earth intermetallics; crystallography; magnetism; single-crystal growth; resistivity.

\section{Introduction}

Rare earth based intermetallic compounds have gained considerable interest in the last few decades because of their interesting properties such as superconductivity, ${ }^{1}$ heavy fermions, ${ }^{2}$ Kondo behaviour, ${ }^{3}$ magnetoresistance ${ }^{4}$ etc. While, the existing databases such as inorganic crystal structure database ${ }^{5}$ and Pearson's crystal data ${ }^{6}$ contain mainly $\mathrm{Ce}, \mathrm{Nd}$, $\mathrm{Pr}$ and $\mathrm{Gd}$ compounds, only a few samarium-based compounds were reported for the above-mentioned properties. A few important examples are $\mathrm{SmRuSn}_{3}$ which crystallizes in the

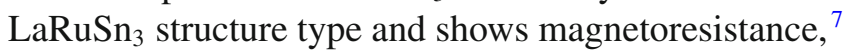
$\mathrm{Sm}_{8} \mathrm{Ru}_{12} \mathrm{Al}_{53} \mathrm{Si}_{17}$ which crystallizes in its own structure type and has two ferromagnetic orderings at $10 \mathrm{~K}$ and $20 \mathrm{~K}^{8}$ and $\mathrm{SmMn}_{2} \mathrm{Ge}_{2}$ which crystallizes in the $\mathrm{CeAl}_{2} \mathrm{Ga}_{2}$ structure type and has two magnetic sublattice exhibiting giant magnetoresistance behaviour which is associated with multiple magnetic phase transitions. ${ }^{9,10}$

During the course of our studies on $R E-\mathrm{Cu}$-In phases based on the overview of the chemical and physical properties of the many $R E_{\mathrm{x}} \mathrm{Cu}_{\mathrm{y}} \mathrm{In}_{\mathrm{z}}$ phases given in the review by Kalychak et al., ${ }^{11}$ we have observed rodshaped single crystals of $\mathrm{SmCu}_{6} \mathrm{In}_{6}$ from excess indium metal. A few compounds were reported within the $\mathrm{Sm}-\mathrm{Cu}$-In family. $\mathrm{SmCu}_{2} \mathrm{In}$ which crystallizes in the $\mathrm{MnCu}_{2} \mathrm{Al}$ structure type has two antiferromagnetic

*For correspondence phase transitions observed at 2.0 and $3.7 \mathrm{~K} .{ }^{12,13}$ The other compounds are $\mathrm{SmCu}_{0.5} \mathrm{In}_{1.5}$ and $\mathrm{Sm}_{2} \mathrm{Cu}_{2} \mathrm{In}$ briefly studied using powder $\mathrm{X}$-ray diffraction (XRD). ${ }^{14,15} \mathrm{SmCu}_{5.1} \mathrm{In}_{6.9}$, reported only for the powder XRD studies, ${ }^{16,17}$ crystallizes in the $\mathrm{CeMn}_{4} \mathrm{Al}_{8}$ type structure, ${ }^{18}$ which is a modified superstructure of the $\mathrm{ThMn}_{12}$ structure type ${ }^{19}$ with space group I4/mmm. A recent study on $\mathrm{RECu}_{6} \mathrm{In}_{6}(\mathrm{RE}=\mathrm{Y}, \mathrm{Ce}, \mathrm{Pr}, \mathrm{Nd}$, $\mathrm{Gd}, \mathrm{Tb}, \mathrm{Dy})$ by Pöttgen and co-workers revealed the copper-indium ordering in this family using split positions of copper and indium at $8 j$ position. ${ }^{20}$ Among these compounds only the Sm compound was missing and very recently we have reported the crystal structure of $\mathrm{YbCu}_{6} \mathrm{In}_{6}$ and mixed valence behaviour of $\mathrm{Yb}$ in the $\mathrm{YbCu}_{6-\mathrm{x}} \operatorname{In}_{6+\mathrm{x}}(x=0,1$ and 2$)$ solid solution. ${ }^{21}$

We report the metal flux synthesis and crystal structure of $\mathrm{SmCu}_{6} \mathrm{In}_{6}$ using single crystal XRD data. After establishing the crystal structure, we have checked the existence of $\mathrm{SmCu}_{6-\mathrm{x}} \mathrm{In}_{6+\mathrm{x}}$ solid solution by changing the $\mathrm{Cu}$ to In ratio. Three compounds of $\mathrm{SmCu}_{6-x} \operatorname{In}_{6+x}$ ( $x=0,1$ and 2 ) were successfully synthesized using the arc melting technique. The phase purity of these compounds was checked by powder XRD and scanning electron microscopy (SEM)/energy dispersive spectrum (EDS). We also report physical properties such as magnetic susceptibility and electrical resistivity of all compounds. Structural variation due to different $\mathrm{Cu}$ to $\mathrm{In}$ ratio strongly influences the magnetic properties in these compounds. 


\section{Experimental}

\subsection{Synthesis}

The following reagents were used as purchased from Alfa-Aesar Co. Ltd. without further purification: Sm (in the form of ingots, 99.99\%), $\mathrm{Cu}$ (ingots, $99.99 \%$ ) and In (shots, 99.99\%).

2.1a Metal flux synthesis of $\mathrm{SmCu}_{6} \mathrm{In}_{6}$ : High quality single crystals of $\mathrm{SmCu}_{6} \mathrm{In}_{6}$ were obtained by combining samarium metal $(0.4 \mathrm{~g})$, copper $(0.084 \mathrm{~g})$, and indium $(1.5 \mathrm{~g})$ in an alumina crucible. The crucible was placed in a $13 \mathrm{~mm}$ fused silica tube, which was flamesealed under a vacuum of $10^{-3}$ torr, to prevent oxidation during heating. The reactants were then heated to $1000^{\circ} \mathrm{C}$ over $10 \mathrm{~h}$, maintained at that temperature for $5 \mathrm{~h}$ to allow proper homogenization, then cooled to $850^{\circ} \mathrm{C}$ in $10 \mathrm{~h}$ and kept at this temperature for $48 \mathrm{~h}$. Finally, the sample was allowed to slowly cool to $30^{\circ} \mathrm{C}$ over $48 \mathrm{~h}$. The reaction product was isolated from the excess indium flux by heating at $450^{\circ} \mathrm{C}$ and subsequently centrifuging through a coarse frit. Any remaining flux was removed by immersion and sonication in glacial acetic acid for $24 \mathrm{~h}$. The final crystalline product was rinsed with water and dried with acetone. This method produced the target compound with ca. $99 \%$ purity and in a low yield on the basis of the initial amount of Sm metal used in the reaction. Shining rod-shaped single crystals up to $0.5 \mathrm{~mm}$ in length were stable in air, and no decomposition was observed even after several weeks. These crystals were carefully selected for elemental analysis and structural characterization.

$2.1 \mathrm{~b}$ Synthesis of $\operatorname{SmCu}_{6-x} \operatorname{In}_{6+x}(x=0,1$ and 2) by arc melting: After establishing the crystal structure of $\mathrm{SmCu}_{6} \mathrm{In}_{6}$, single phases of $\mathrm{SmCu}_{6-\mathrm{x}} \operatorname{In}_{6+\mathrm{x}}(x=0,1,2)$ were prepared by arc melting in Ar-atmosphere. Samples were melted repeatedly in the same atmosphere to ensure homogeneity. Weight losses of the final material were found to be less than $1 \%$. X-ray powder diffraction measurements showed that all compounds are single phases with the expected structure type. Samples obtained via arc melting method were used for physical property studies.

\subsection{Elemental analysis}

Semi-quantitative microanalyses of the samples were performed with a scanning Leica 220i electron microscope (SEM) equipped with Bruker $129 \mathrm{eV}$ energy dispersive X-ray analyser. Data were acquired with an accelerating voltage of $20 \mathrm{kV}$ and in $90 \mathrm{~s}$ accumulation time. EDS analysis performed on visibly clean surfaces of the single crystal obtained by flux method gave the atomic composition 1:3.9(1):7.9(1), 1:4.8(1):6.8(1) and 1:6.0(1):5.9(1) for $\mathrm{SmCu}_{4} \mathrm{In}_{8}, \mathrm{SmCu}_{5} \mathrm{In}_{7}$ and $\mathrm{SmCu}_{6} \mathrm{In}_{6}$, respectively. SEM image of a typical rodlike crystal of $\mathrm{SmCu}_{6} \mathrm{In}_{6}$ grown by flux method is shown in figure 1. EDS analyses on the clean surfaces of ingot samples obtained by arc melting method is also in good agreement with the starting composition.

\subsection{Powder XRD}

Phase identity and purity of the $\mathrm{SmCu}_{6-\mathrm{x}} \operatorname{In}_{6+\mathrm{x}}(x=0,1$ and 2) samples were determined by powder XRD experiments that were carried out with a Bruker D8 Discover diffractometer using $\mathrm{Cu}-\mathrm{K} \alpha$ radiation $(\lambda=1.5406 \AA)$. Le Bail profile analysis in the Fullprof suite was used to refine the XRD data. The background was estimated by 6-coefficient polynomial function consisting of 9 coefficients, and peak shapes were described by a pseudoVoigt function with 9 varying profile coefficients. A zero error factor and shape were refined. Experimental powder pattern of all samples is in good agreement with the patterns calculated from the single-crystal X-ray data (supporting information).

\subsection{Single crystal XRD}

Suitable single crystal of $\mathrm{SmCu}_{6} \mathrm{In}_{6}$ was mounted on a thin glass fibre with commercially available super glue. X-ray single crystal structural data of $\mathrm{SmCu}_{6} \operatorname{In}_{6}$ were collected on a Bruker Smart-CCD diffractometer equipped with a normal focus, $2.4 \mathrm{~kW}$ sealed tube $\mathrm{X}$-ray source with graphite monochromatic $\mathrm{Mo}-\mathrm{K} \alpha$ radiation

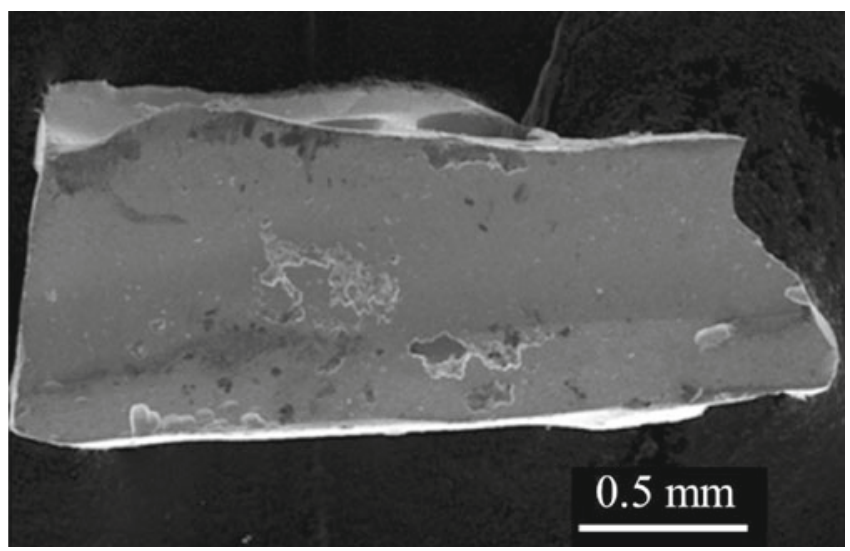

Figure 1. SEM image of a typical single crystal of $\mathrm{SmCu}_{6} \mathrm{In}_{6}$. 
( $\lambda=0.71073 \AA)$ operating at $50 \mathrm{kV}$ and $30 \mathrm{~mA}$, with $\omega$ scan mode. The structure was solved by SHELXS 97 and refined by a full matrix least-squares method using SHELXL. Details of crystallographic data are provided in tables 1 to 4.

\subsection{Structure refinement}

Atomic parameters of $\mathrm{SmCu}_{5.1} \mathrm{In}_{6.9},{ }^{15}$ were taken as starting parameters and the structure was refined using SHELXL-97 (full-matrix least-squares on $F^{2}$ ), with

Table 1. Crystal data and structure refinement for $\mathrm{SmCu}_{6} \mathrm{In}_{6}$ at 293(2) K.

\begin{tabular}{|c|c|}
\hline Empirical formula & $\mathrm{SmCu}_{6} \operatorname{In}_{6}$ \\
\hline Formula weight & 1220.51 \\
\hline Temperature & $293(2) \mathrm{K}$ \\
\hline Wavelength & $0.71073 \AA$ \\
\hline Crystal system & Tetragonal \\
\hline Space group & $I 4 / \mathrm{mmm}$ \\
\hline \multirow[t]{3}{*}{ Unit cell dimensions } & $a=9.2036(3) \AA, \alpha=90.00^{\circ}$ \\
\hline & $b=9.2036(3) \AA, \beta=90.00^{\circ}$ \\
\hline & $c=5.4232(3) \AA, \gamma=90.00^{\circ}$ \\
\hline Volume & $459.38(3) \AA^{3}$ \\
\hline$Z$ & 2 \\
\hline Density (calculated) & $8.824 \mathrm{~g} / \mathrm{cm}^{3}$ \\
\hline Absorption coefficient & $34.507 \mathrm{~mm}^{-1}$ \\
\hline $\mathrm{F}(000)$ & 1060 \\
\hline Crystal size & $0.10 \times 0.05 \times 0.05 \mathrm{~mm}^{3}$ \\
\hline$\Theta$ range for data collection & 3.13 to $32.06^{\circ}$ \\
\hline Index ranges & $\begin{aligned}-13<=h & <=13,-13<=k<=10 \\
-8 & <=l<=7\end{aligned}$ \\
\hline Reflections collected & 2164 \\
\hline Independent reflections & $264\left[R_{\mathrm{int}}=0.0543\right]$ \\
\hline Completeness to $\theta=32.17^{\circ}$ & $100 \%$ \\
\hline Refinement method & Full-matrix least-squares on $F^{2}$ \\
\hline Data/restraints/parameters & $264 / 0 / 17$ \\
\hline Goodness-of-fit & 1.112 \\
\hline Final $R$ indices $[>2 \sigma(\mathrm{I})]^{\mathrm{a}}$ & $R_{\mathrm{obs}}=0.0281, w R_{\mathrm{obs}}=0.0653$ \\
\hline$R$ indices (all data) & $R_{\mathrm{all}}=0.0283, w R_{\mathrm{all}}=0.0653$ \\
\hline Extinction coefficient & $0.0117(14)$ \\
\hline Largest difference peak and hole & 2.265 and $-3.339 \mathrm{e} \cdot \AA^{-3}$ \\
\hline
\end{tabular}

Table 2. Atomic coordinates $\left(\times 10^{4}\right)$ and equivalent isotropic displacement parameters $\left(\AA^{2} \times 10^{3}\right)$ for $\mathrm{SmCu}_{6} \mathrm{In}_{6}$ at $293(2) \mathrm{K}$ with estimated standard deviations in parentheses.

\begin{tabular}{lccrrrr}
\hline Label & Wyckoff site & $x$ & $y$ & $z$ & Occupancy & $U_{\text {eq }}^{*}$ \\
\hline $\mathrm{Sm}$ & $2 a$ & 0 & 0 & 0 & 1 & $6(1)$ \\
$\mathrm{Cu}(1)$ & $8 f$ & 2500 & 2500 & 2500 & 1 & $10(1)$ \\
$\mathrm{Cu}(2)$ & $8 j$ & $2697(5)$ & 5000 & 0 & 0.5 & $10(2)$ \\
$\mathrm{In}(1)$ & $8 i$ & $3409(2)$ & 0 & 0 & 1 & $8(1)$ \\
$\mathrm{In}(2)$ & $8 j$ & $3123(3)$ & 5000 & 0 & 0.5 & $10(1)$ \\
\hline
\end{tabular}

${ }^{*} U_{\text {eq }}$ is defined as one third of the trace of the orthogonalized $U_{\mathrm{ij}}$ tensor 
Table 3. Anisotropic displacement parameters $\left(\AA^{2} \times 10^{3}\right)$ for $\mathrm{SmCu}_{6} \mathrm{In}_{6}$ at 293(2) $\mathrm{K}$ with estimated standard deviations in parentheses.

\begin{tabular}{lrrrlll}
\hline Label & $U_{11}$ & $U_{22}$ & $U_{33}$ & $U_{12}$ & $U_{13}$ & $U_{23}$ \\
\hline Sm & $6(1)$ & $6(1)$ & $4(1)$ & 0 & 0 & 0 \\
$\mathrm{Cu}(1)$ & $11(1)$ & $11(1)$ & $7(1)$ & $2(1)$ & $2(1)$ & $2(1)$ \\
$\mathrm{Cu}(2)$ & $23(3)$ & $8(2)$ & $5(2)$ & 0 & 0 & 0 \\
$\operatorname{In}(1)$ & $8(1)$ & $9(1)$ & $14(1)$ & 0 & 0 & 0 \\
$\operatorname{In}(2)$ & $8(2)$ & $6(1)$ & $2(1)$ & 0 & 0 & 0 \\
\hline
\end{tabular}

Anisotropic displacement factor exponent takes the form: $-2 \pi^{2}\left[h^{2} a^{* 2} U_{11}+\ldots+2 h k a^{*} b^{*} U_{12}\right]$.

anisotropic atomic displacement parameters for all atoms. As a check for the correct composition, occupancy parameters were refined in a separate series of least-squares cycles. There are four different atomic positions in $\mathrm{SmCu}_{6} \mathrm{In}_{6}$ structure, one for $\mathrm{Sm}$ and other three (Wyckoff positions $8 f, 8 i, 8 j$ ) are shared by In and $\mathrm{Cu}$ atoms. Refinement of the occupancy parameters revealed full occupancy at the $8 f$ and $8 i$ sites with copper and indium, respectively. However, $8 j$ sites revealed occupancy by approximately $50 \%$ copper and $50 \%$ indium and huge anisotropic displacement parameters $U_{11}$, which is seven times larger than $U_{22}$. Further, we used the split model for $8 j$ sites similar to the refinement of $\mathrm{RECu}_{6} \mathrm{In}_{6}{ }^{20}$ and refined the structure occupying $\mathrm{Cu}$ and In, fully occupied individually in one site each. Sm atoms occupy the $2 a$ site of $4 / \mathrm{mmm}$ point symmetry, $\mathrm{Cu} 1$ atoms occupy the $8 f$ site of $2 / m$ point symmetry, In 1 atoms occupy the $8 i$ site of $m 2 m$ point symmetry and $8 j$ site splits for $\mathrm{Cu}$ and $\mathrm{In}$ atoms of $m 2 m$ point symmetry. The refinement then smoothly converged to the normal residuals. Data collection and refinement parameters are summarized in table 1. Atomic coordinates and equivalent thermal parameters, anisotropic displacement parameters and important bond lengths are listed in tables 2, 3 and 4, respectively. Further information

Table 4. Selected bond lengths ( $\AA$ ) for $\mathrm{SmCu}_{6} \mathrm{In}_{6}$ at 293(2) K with estimated standard deviations in parentheses.

\begin{tabular}{lccc}
\hline Label & Distances & Label & Distances \\
\hline $\mathrm{Sm}-\operatorname{In}(1)$ & $3.1378(7)$ & $\mathrm{Cu}(2)-\operatorname{In}(1)$ & $2.93(3)$ \\
$\mathrm{Sm}-\operatorname{In}(2)$ & $3.215(7)$ & $\mathrm{Cu}(1)-\operatorname{In}(1)$ & $2.798(4)$ \\
$\mathrm{Cu}(2)-\mathrm{Cu}(2)$ & $2.918(7)$ & $\mathrm{Cu}(1)-\mathrm{Cu}(1)$ & $2.7116(5)$ \\
$\mathrm{In}(2)-\operatorname{In}(2)$ & $2.444(19)$ & $\mathrm{Cu}(1)-\mathrm{Cu}(2)$ & $2.682(5)$ \\
$\mathrm{Cu}(2)-\operatorname{In}(2)$ & $2.69(4)$ & $\mathrm{In}(1)-\operatorname{In}(1)$ & $2.9279(12)$ \\
$\mathrm{Cu}(1)-\operatorname{In}(2)$ & $2.731(3)$ & & \\
\hline
\end{tabular}

on the structure refinement is available from: Fachinformationszentrum Karlsruhe, D-76344 EggensteinLeopoldshafen (Germany), by quoting the Registry No. CSD-424639.

\subsection{Magnetic measurements}

Magnetic measurements of $\mathrm{SmCu}_{6-\mathrm{x}} \operatorname{In}_{6+\mathrm{x}}(x=0,1$ and 2) were carried out on a Quantum Design MPMSSQUID magnetometer. Measurements were performed on polycrystals, which were ground and screened
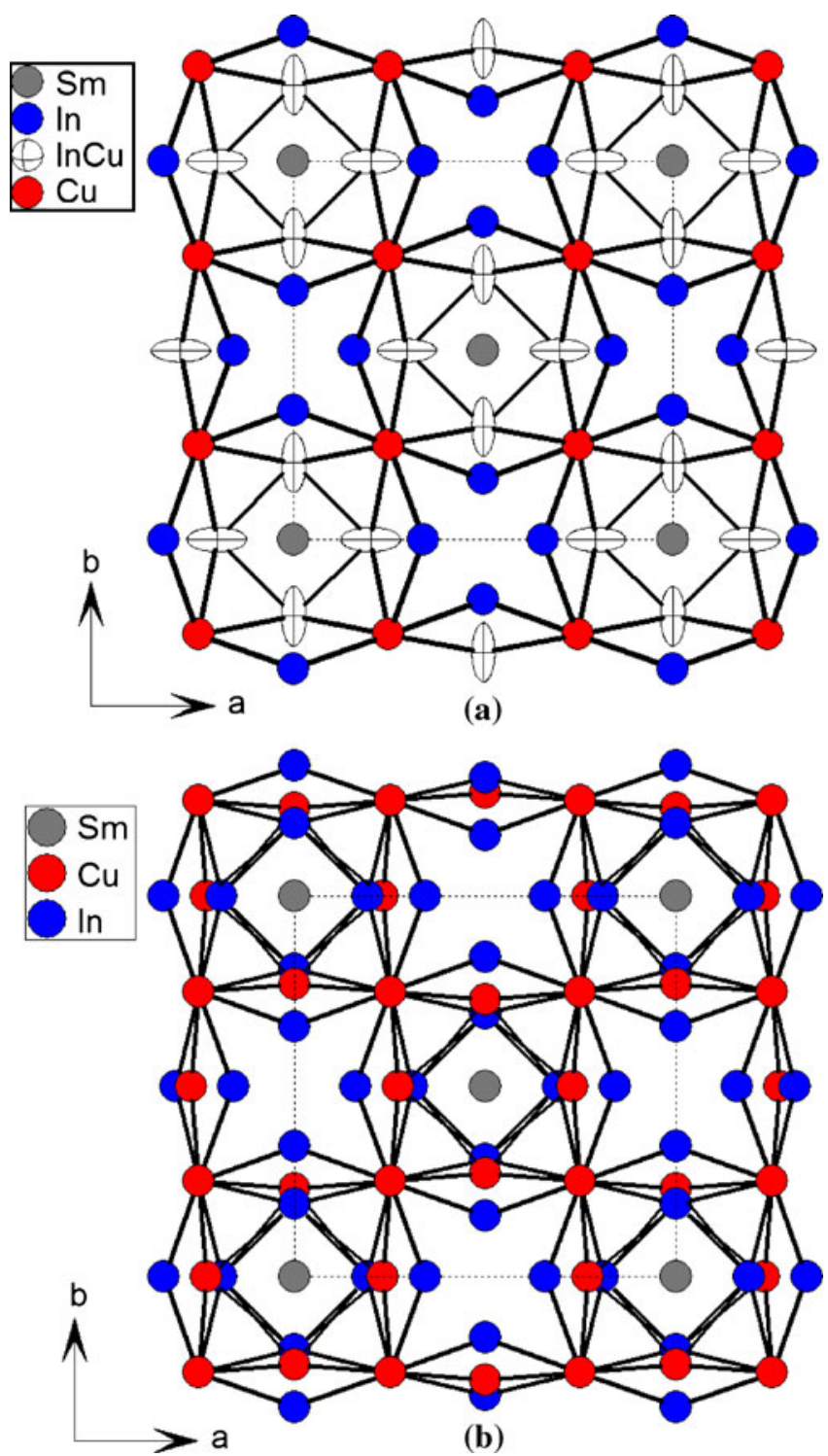

Figure 2. Structure of $\mathrm{SmCu}_{6} \mathrm{In}_{6}$ as viewed along the $c$-axis; the unit cell is outlined as dot lines. (a) Parameters obtained from the refinement using mixed atomic positions of $\mathrm{Cu}$ and $\mathrm{In}$ at $8 j$ and (b) Cigar-shaped $\mathrm{Cu}_{0.5} \mathrm{In}_{0.5}$ positions resolved by the split model keeping inner square uniquely occupied by copper and an outer one uniquely occupied by indium atoms. 
by powder XRD to verify phase identity and purity. Temperature-dependent data were collected for fieldcooled mode (FC) between 2 and $300 \mathrm{~K}$ with an applied field of $1 \mathrm{kOe}$. Magnetization data were also collected for $\mathrm{SmCu}_{6-\mathrm{x}} \mathrm{In}_{6+\mathrm{x}}$ at $2 \mathrm{~K}$ and $20 \mathrm{~K}$ with field sweeping from -55 to $55 \mathrm{kOe}$.

\subsection{Electrical resistivity}

Resistivity measurements were performed on $\mathrm{SmCu}_{6-\mathrm{x}} \operatorname{In}_{6+\mathrm{x}}(x=0,1$ and 2$)$ with a conventional $\mathrm{AC}$ four probe set-up. Four very thin copper wires were glued to the pellet using a strongly conducting silver epoxy paste. Data were collected in the temperature range of 3-300 K using a commercial Quantum Design Physical Property Measurement System (QD-PPMS).

\section{Results and discussions}

\subsection{Crystal chemistry}

$\mathrm{SmCu}_{6} \mathrm{In}_{6}$ crystallizes in the tetragonal $\mathrm{YCu}_{6} \mathrm{In}_{6}$ type structure (space group $I 4 / \mathrm{mmm}$ ), ${ }^{20}$ which is an ordered structure of the $\mathrm{CeMn}_{4} \mathrm{Al}_{8}$ type. The crystal structure of $\mathrm{SmCu}_{6} \mathrm{In}_{6}$ along [001] direction is shown in figure 2. The view of $\mathrm{SmCu}_{6} \mathrm{In}_{6}$ unit cell with the parameters obtained from the refinement using mixed atomic position at $8 j$ is shown in figure 2a. Cigar-shaped $\mathrm{Cu}_{0.5} \operatorname{In}_{0.5}$ positions resolved by the split model keeping inner square uniquely occupied by copper and an outer one uniquely occupied by indium atoms is shown in figure 2b. Crystal structure of $\mathrm{SmCu}_{6} \mathrm{In}_{6}$ is composed of pseudo-Frank-Kasper cages $\left[\mathrm{Cu}_{8} \mathrm{In}_{8}\right]$ occupying one samarium atom in each ring to form a stable structure (figure 3). These pseudo-Frank-Kasper cages are shared through the corner copper atoms along $a b$ plane resulting in a three-dimensional network.
A slight distortion in $\mathrm{SmCu}_{6} \mathrm{In}_{6}$ is clearly evident in comparison of the coordination environments of $\mathrm{Mn}$ in $\mathrm{CeMn}_{4} \mathrm{Al}_{8}$ structure and $\mathrm{Cu}$ in $\mathrm{SmCu}_{6} \mathrm{In}_{6}$ structure (figure 4). The coordination environment of indium atoms is formed as a 14-vertex Frank-Kasper cage (not shown in figure). Split atoms are in the distorted icosahedrons geometry composed of 12 atoms of which two are $\mathrm{Sm}$ atoms and the remaining ten atoms are shared by $\mathrm{Cu}$ and In atoms. All icosahedrons and Frank-Kasper cages are slightly distorted compared to the $\mathrm{CeMn}_{4} \mathrm{Al}_{8}$ compound.

The shortest distance of Sm-In (3.1378(7) $\AA$ ) which is smaller than the calculated distances of $3.263 \AA,{ }^{22}$ suggests a strong covalent bond between $\mathrm{Sm}$ and In atoms; however, the shortest distance between $\mathrm{Sm}$ and $\mathrm{Cu}$ atoms (3.5251(3) $\AA$ ) is substantially larger than the theoretical value of $3.084 \AA{ }^{23}$ indicates weak interaction between them. The shortest $\mathrm{Cu}-\mathrm{In}$ distance in $\mathrm{SmCu}_{6} \operatorname{In}_{6} 2.753(4)$ is $\AA$ close to the distances observed in other $\mathrm{RECu}_{6} \mathrm{In}_{6}$ compounds. ${ }^{20}$ Relatively small InIn distances (2.483(4) $\AA$ ) are due to the split model refinement which allows the formation of suitable bond lengths between copper and indium atoms.

\subsection{Physical properties}

3.2a Magnetism: Magnetic susceptibility measurements were made on polycrystalline sample of $\mathrm{SmCu}_{6-\mathrm{x}} \operatorname{In}_{6+\mathrm{x}}(x=0,1$ and 2$)$ obtained by arc melting. Temperature-dependent magnetic susceptibility at an applied field of $1 \mathrm{kOe}$ is shown in figure 5 and inverse molar magnetic susceptibility data versus temperature is shown in figure 6. All compounds show weak paramagnetism in the temperature range of 50$300 \mathrm{~K}$ (figure 5), which is typical for samarium-based intermetallics. ${ }^{17}$ Inverse molar susceptibility $\left(\chi_{m}\right)$ of the compounds $\mathrm{SmCu}_{6} \mathrm{In}_{6}$ and $\mathrm{SmCu}_{5} \mathrm{In}_{7}$ obeys modified

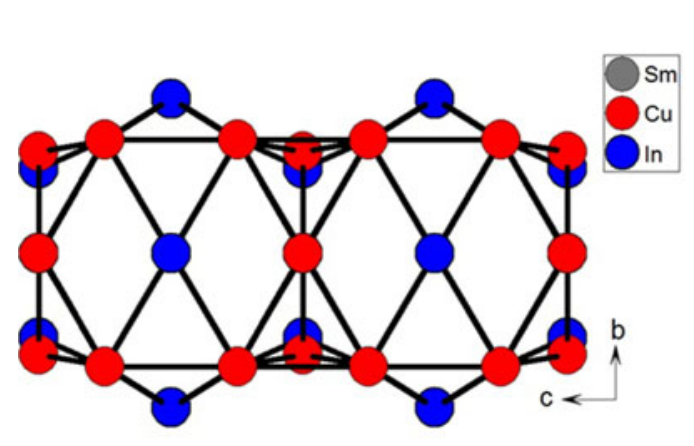

(a)

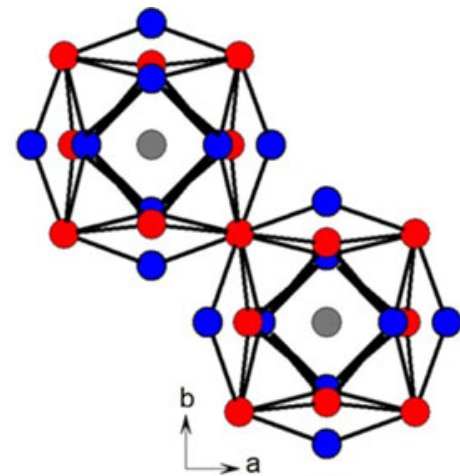

(b)

Figure 3. Pseudo-Frank-Kasper cages in $\mathrm{SmCu}_{6} \mathrm{In}_{6}$ are shared through the (a) edges of the split atoms and (b) corner of $\mathrm{Cu}$ atoms along ab plane. 


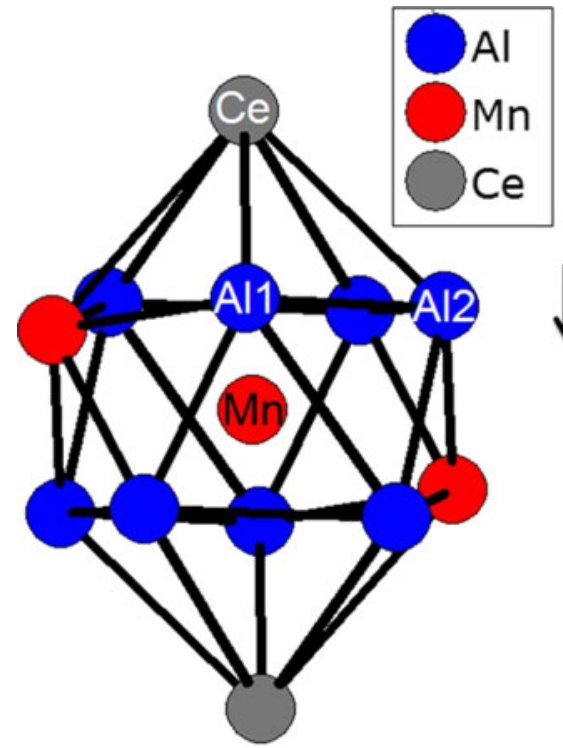

(a)

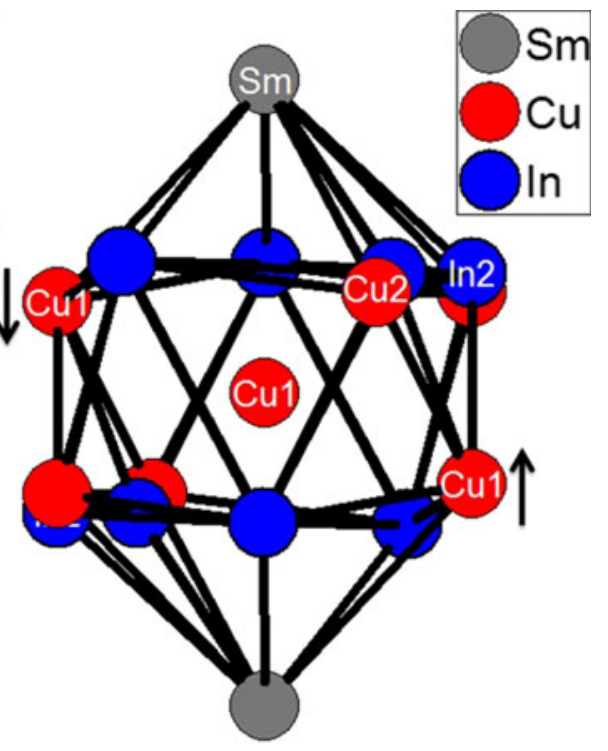

(b)

Figure 4. Comparison of icosahedron polyhedra of (a) $\mathrm{Mn}$ in $\mathrm{CeMn}_{4} \mathrm{Al}_{8}$ and (b) $\mathrm{Cu}$ in $\mathrm{SmCu}_{6} \mathrm{In}_{6}$.

Curie-Weiss law, $\chi=C /(T-\theta)+\chi_{0}$ above $50 \mathrm{~K}$ and an antiferromagnetic ordering found at $7.8 \mathrm{~K}$. On the other hand, there is no long range magnetic ordering found down to $2 \mathrm{~K}$ in $\mathrm{SmCu}_{4} \mathrm{In}_{8}$ and non-linear curve indicates a probable valence fluctuation in this compound. In all compounds, susceptibility rises with decreasing temperature as seen in paramagnets, but $\mathrm{SmCu}_{5} \mathrm{In}_{7}$ and $\mathrm{SmCu}_{4} \mathrm{In}_{8}$ show a sudden increase over a very low temperature in the range of $2-10 \mathrm{~K}$. In contrast, magnetic susceptibility plot of $\mathrm{SmCu}_{4} \mathrm{In}_{8}$ contains three different linear regions, i.e., 10 $180 \mathrm{~K}\left(1.1 \mu_{\mathrm{B}}\right), 170-220 \mathrm{~K}\left(0.81 \mu_{\mathrm{B}}\right)$ and $260-300 \mathrm{~K}$ $\left(0.22 \mu_{\mathrm{B}}\right)$. A significant deviation at the lower temperature can be attributed to crystal field effects. It is interesting to note that the effective Bohr magneton number $\left(\mu_{\text {eff }}\right)$ observed from the linear fit using modified Curie-Weiss law is $0.88 \mu_{\mathrm{B}}$ (in the range $10-300 \mathrm{~K})$ per $\mathrm{Sm}$ atom for $\mathrm{SmCu}_{6} \mathrm{In}_{6}$ close to the

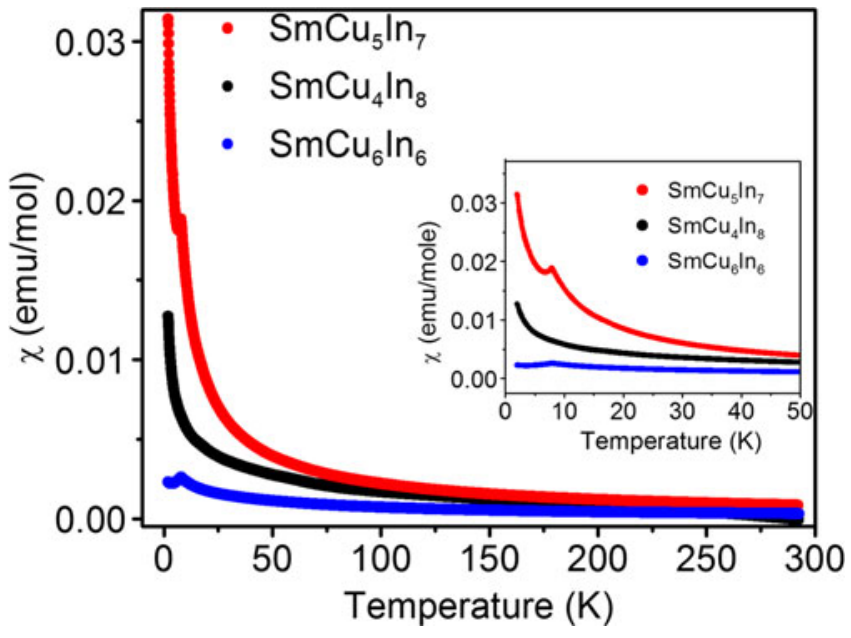

Figure 5. Temperature-dependent magnetic susceptibility, $\chi$, of $\mathrm{SmCu}_{4} \mathrm{In}_{8}, \mathrm{SmCu}_{5} \mathrm{In}_{7}$ and $\mathrm{SmCu}_{6} \mathrm{In}_{6}$. Inset figure shows the low temperature behaviour.

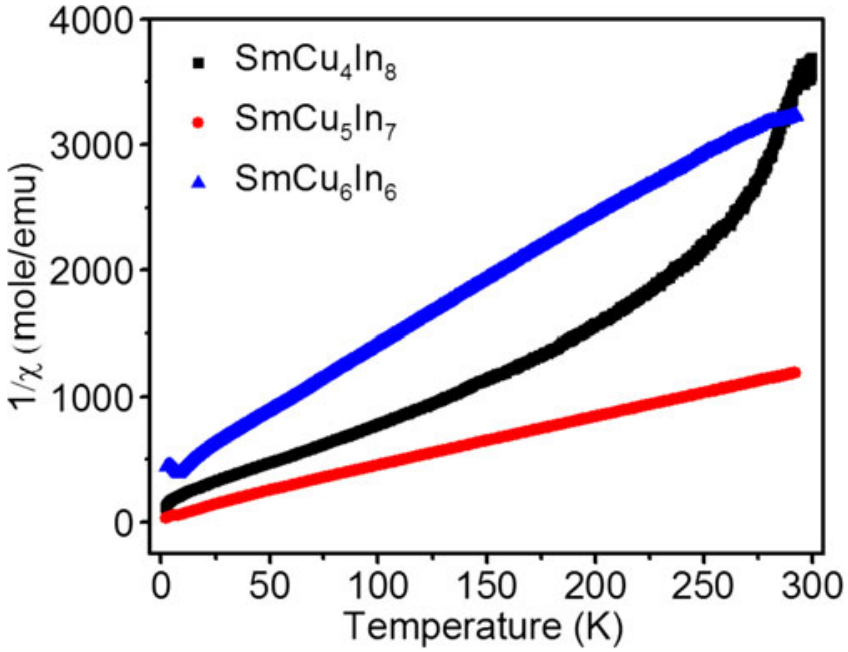

Figure 6. Temperature dependence of the modified reciprocal magnetic susceptibility, $1 / \chi$, of the $\mathrm{SmCu}_{4} \mathrm{In}_{8}$, $\mathrm{SmCu}_{5} \mathrm{In}_{7}$ and $\mathrm{SmCu}_{6} \mathrm{In}_{6}$ samples. 
calculated magnetic moment of $0.84 \mu_{\mathrm{B}}$ for a free trivalent samarium ion. ${ }^{24}$ Magnetic moment of $0.84 \mu_{\mathrm{B}}$ for free samarium ion was calculated using Hund's rule using antiparallel spin $(S=5 / 2)$ and orbital $(L=5)$ angular momenta. In contrast, magnetic moment for $\mathrm{Sm}$ in $\mathrm{SmCu}_{5} \mathrm{In}_{7}$ is obtained as $1.43 \mu_{\mathrm{B}} / \mathrm{Sm}$ atom. Here, Hund's rules are expected to be unreliable in this system because another $\mathrm{J}$ multiplet lies just above this free-ion ground state of samarium, and crystalline electric field effects frequently lead to different ground states and in pure Sm metal, the paramagnetic moment is observed to be $1.5 \mu_{\mathrm{B}}$, instead of the expected value of $0.84 \mu_{\mathrm{B}} \cdot{ }^{24}$ Calculated values of paramagnetic Curie temperature $\left(\theta_{\mathrm{p}}\right)$ are $64.038 \mathrm{~K}$, $-21.53 \mathrm{~K}$ and $-52.08 \mathrm{~K}$ for $\mathrm{SmCu}_{4} \mathrm{In}_{8}, \mathrm{SmCu}_{5} \mathrm{In}_{7}$ and $\mathrm{SmCu}_{6} \mathrm{In}_{6}$, respectively, suggesting strong ferromagnetic interactions in $\mathrm{SmCu}_{4} \mathrm{In}_{8}$ and antiferromagnetic interactions in other two compounds. In general, compounds crystallizing in the $\mathrm{CeMn}_{4} \mathrm{Al}_{8}$ structure type, show disorder at the $\mathrm{Mn}$ and $\mathrm{Al}$ sites which affects the magnetic behaviour in the solid solution and it was previously reported for $\mathrm{LaMn}_{4} \mathrm{Al}_{8}{ }^{25}$ and very recently for $\mathrm{YbCu}_{6-\mathrm{x}} \operatorname{In}_{6+\mathrm{x}}(x=0,1,2) .{ }^{21}$ Assuming $\mathrm{Cu}$ and $\mathrm{In}$ are non-magnetic elements in the system, this large difference in magnetic moment could be possibly associated with the structural behaviour. Many detailed structural studies such as neutron diffraction and magnetic Compton scattering measurement could give an insight to the structure-property relations in these compounds.

Field dependence of the magnetization, $M(H)$ for $\mathrm{SmCu}_{6-\mathrm{x}} \operatorname{In}_{6+\mathrm{x}}(x=0,1,2)$ ground samples were measured at $2 \mathrm{~K}$ and $20 \mathrm{~K}$ is shown in figure 7 . Data measured at $20 \mathrm{~K}$ exhibits linear behaviour and no signs of saturation up to the highest attainable field of $60 \mathrm{kOe}$. Magnetization curve at $2 \mathrm{~K}$ (within the magnetic ordering) shows a slight field-dependent response up to $\sim 30 \mathrm{kOe}$, which continues to rise slowly up to the highest obtainable field $(60 \mathrm{kOe})$. For all three compounds, magnetic moment does not saturate even at the highest applied magnetic field $(60 \mathrm{kOe})$.

3.2b Electrical resistivity: The normal state temperature-dependent reduced electrical resistivities of $\mathrm{SmCu}_{6-\mathrm{x}} \operatorname{In}_{6+\mathrm{x}}(x=0,1,2)$ shown in figure 8 . Resistivity values obtained at room temperature for the samples $\mathrm{SmCu}_{6} \mathrm{In}_{6}, \mathrm{SmCu}_{5} \mathrm{In}_{7}$ and $\mathrm{SmCu}_{4} \mathrm{In}_{8}$ are 3700,330 and $380 \mu \Omega \mathrm{cm}$, respectively. The large value for the sample $\mathrm{SmCu}_{6} \mathrm{In}_{6}$ probably occurs due to the presence of several micro cracks and were irregularly shaped, so only the reduced resistivity $\left(\rho / \rho_{300}\right)$ is plotted here. The $\rho / \rho_{300}$ continuously decreases linearly with decreasing temperature, typical for metallic systems, ${ }^{26,27}$ but without any long range magnetic ordering. At low
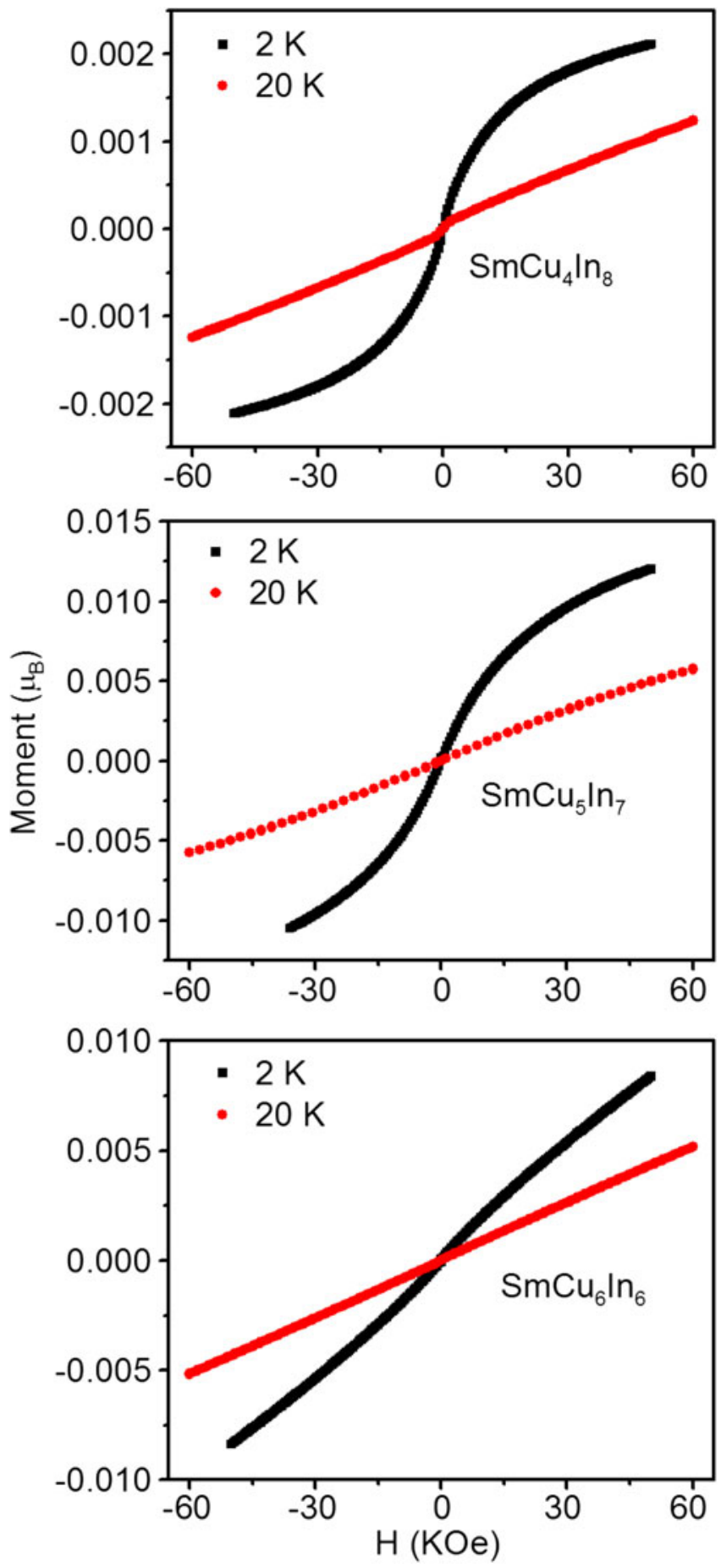

Figure 7. Magnetization as a function of applied magnetic field at $2 \mathrm{~K}$ and $20 \mathrm{~K}$ for a polycrystalline sample of $\mathrm{SmCu}_{4} \mathrm{In}_{8}, \mathrm{SmCu}_{5} \mathrm{In}_{7}$ and $\mathrm{SmCu}_{6} \mathrm{In}_{6}$.

temperature, in the range of $0-50 \mathrm{~K}, \rho(T)$ data can be fitted to the power law function, $\rho=\rho_{0}+A T^{n}$, where $\rho_{0}$ is the residual resistivity expressed in units of $\Omega$ $\mathrm{cm}, A$ and $n$ are the fitting parameters. Values obtained from the fit are shown in figure 8. According to Fermiliquid theory, at low temperatures, resistivity varies as $\rho=\rho_{0}+A T^{2}$. Experimentally, it has been observed 


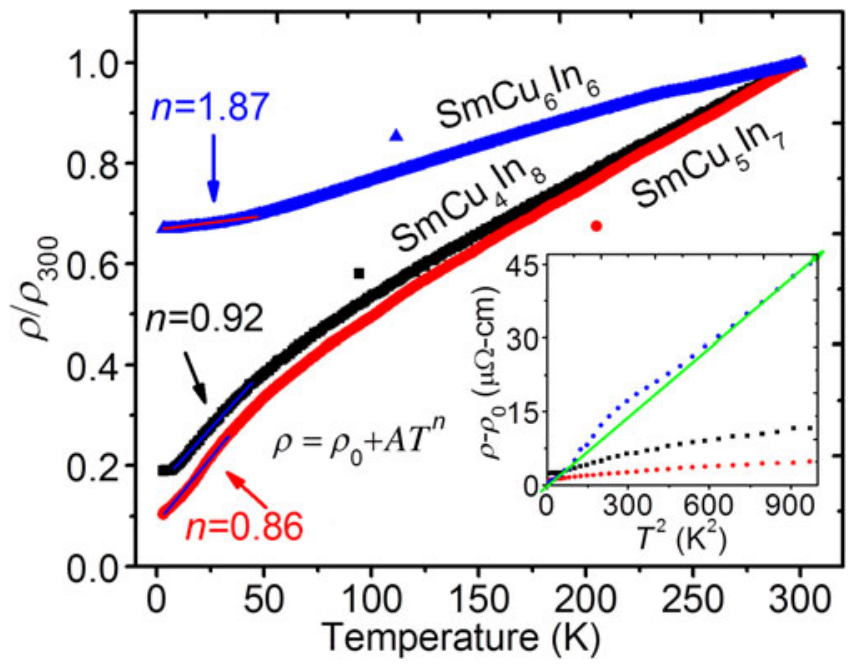

Figure 8. Temperature-dependent electrical resistivity $\rho(T)$ of $\mathrm{SmCu}_{4} \mathrm{In}_{8}, \mathrm{SmCu}_{5} \mathrm{In}_{7}$ and $\mathrm{SmCu}_{6} \mathrm{In}_{6}$. Inset figure shows the low temperature data fit using the Power law $\rho=\rho_{0}+A T^{n}$.

that when electron-electron scattering dominates over electron-phonon scattering, $\rho \alpha T^{2}$.

The value obtained from the fit power is close to 2 in $\mathrm{SmCu}_{6} \mathrm{In}_{6}$ which is the case for systems exhibiting Fermi liquid state. ${ }^{28,29}$ However, in $\mathrm{SmCu}_{4} \mathrm{In}_{8}$ and $\mathrm{SmCu}_{5} \mathrm{In}_{7}$, the value obtained from the fit power is 0.9299 and 0.8684 , respectively, characteristic of nonFermi liquid state ${ }^{30}$ In order to verify Fermi liquid and non-Fermi liquid behaviour, resistivity data is plotted as $\left(\rho-\rho_{0}\right)$ vs. $T^{2}$ as inset in figure 8 . For $\mathrm{SmCu}_{6} \mathrm{In}_{6}$, linearity in the data confirms a possible Fermi-liquid behaviour at low temperatures, while other two compounds show a deviation from the linearity. Similar kind of behaviour observed in $\mathrm{YbCu}_{6-\mathrm{x}} \mathrm{In}_{6+\mathrm{x}}(x=0,1$ and 2). ${ }^{21}$

\section{Concluding remarks}

High quality single crystals of $\mathrm{SmCu}_{6} \mathrm{In}_{6}$ were obtained by metal flux technique and the crystal structure was studied from crystal XRD data on single crystals. $\mathrm{SmCu}_{6-\mathrm{x}} \operatorname{In}_{6+\mathrm{x}}(x=0,1$ and 2$)$ compounds were obtained from the arc melting characterized by X-ray powder diffraction method. Magnetic susceptibility data of $\mathrm{SmCu}_{6-\mathrm{x}} \mathrm{In}_{6+\mathrm{x}}(x=0,1$ and 2$)$ obeys modified Curie-Weiss law above $50 \mathrm{~K}$ and a substantial difference in the magnetic behaviour of each compounds. This system is one of the classical examples having interesting structure-property relations. One might expect other rare earth based compounds also having similar structure property relations. A much more detailed study such as temperature- and field-dependent magnetic and heat capacity studies are required to monitor the complex magnetic behaviour in this solid solution.

\section{Acknowledgements}

We thank Prof. C N R Rao for his support and guidance. Financial support from the Jawaharlal Nehru Centre for Advanced Scientific Research (JNCASR), the Department of Science and Technology, New Delhi (DST) (Grant SR/S2/RJN-24/2010) and Sheikh Saqr Laboratory, JNCASR, Bangalore is gratefully acknowledged. US thanks the Council of Scientific and Industrial Resources (CSIR), New Delhi for research fellowship. SCP thanks the DST for Ramanujan fellowship. We also thank Mr. Rana, Mr. Bharat and Ms. Selvi for various measurements.

\section{Supplementary information}

Figures S1-S3 and table S1, as supporting information are available at www.ias.ac.in/chemsci website.

\section{References}

1. Fujii H and Kasahara S 2008 J. Phys. Condens. Mat. 20 075202

2. Adroja D T and Malik S K 1991 J. Magn. Magn. Mater. 100126

3. Van daal H J and Buschow K H 1970 J. Phys. Status Solidi A3 853

4. (a) Francisco M C, Malliakas C D, Piccoli P M B, Gutmann M J, Schultz A J and Kanatzidis M G 2010 J. Am. Chem. Soc. 132 8998; (b) Szytula A 1993 Phys. Scripta T49 284; (c) Singh N K, Pecharsky V K and Gschneidner Jr K A 2008 Phys. Rev. B77 054414

5. Inorganic Crystal Structure Database; Fachinformationszentrum Karlsruhe GmbH: Eggenstein-Leopoldshafen, Germany, 2012

6. Villars P and Cenzual K 2010/11 Pearson's Crystal Data-Crystal Structure Database for Inorganic Compounds; ASM International: Materials Park, Ohio, Release

7. Fukuharat T, Sakamoto I and Sato H 1991 J. Phys. Condens. Mat. 38917

8. Sieve B, Chen X Z, Henning R, Brazis P, Kannewurf C R, Cowen J A, Schultz A J and Kanatzidis M G 2001 J. Am. Chem. Soc. 1237040

9. Chaudhary S, Chattopadhyay M K, Singh K J, Roy S B, Chaddah P and Sampathkumaran E V 2002 Phys. Rev. B66 014424

10. Van dover R B, Gyorgy E M, Cava R J, Krajewski J J, Felder R J and Peck W F 1993 Phys. Rev. B47 6134 
11. Kalychak Ya M, Zaremba V I, Pöttgen R, Lukachuk M, Hoffmann R D, Gschneidner Jr. K A, Pecharsky V K and Bünzli J C 2005 Handbook on the physics and chemistry of rare earths (Amsterdam: Elsevier), vol. 34 Chapter 218

12. Sato K, Isikawa Y and Mori K 1992 J. Magn. Magn. Mater. 104-107 1435

13. Felner I 1985 Solid State Commun. 56315

14. Baranyak V M, Dmytrakh O V, Kalychak Y M and Zavalii P Y 1988 Inorg. Mater. 24739

15. Kalychak Y M, Zaremba V I, Baranyak V M, Zavalii P Y, Bruskov V A, Sysa L V and Dmytrakh O V 1990 Inorg. Mater. 2674

16. Suski W, Wochowski K, Bodak O I, Kalychak Ya M, Zaremba V I and Mydlarz T 1997 J. Alloys Compd. 250 642

17. Sysa L V, Kalichak Ya M, Akhmad B and Baranyak V M 1989 Sov. Phys. Crystallogr. 34443

18. Buschow K H J, Van Vucht J H N and Van Den Hoogenhof W W 1976 J. Less-Common Met. 50145

19. Florio J V, Rundle R E and Snow A I 1952 Acta Crystallogr. $\mathbf{5} 449$
20. Zaremba R, Muts I, Hoffmann R D, Kalychak Ya M, Zaremba V I and Pottgen R 2007 J. Solid State Chem. 1802534

21. Subbarao U and Peter S C 2012 Inorg. Chem. 516326

22. Galadzhun Y V, Hoffmann R D, Pöttgen R and Adam M 1999 J. Solid State Chem. 148425

23. Iandelli A 1983 J. Less-Common Met. 90121

24. McCarthy J E, Duffy J A, Detlefs C, Cooper M J and Canfield P C 2000 Phys. Rev. B62 R6073

25. Yamasaki T, Matsui K, Nakamura H and Shiga M 2001 Solid State Commun. 119415

26. He J, Ling G and Jiao Z 2001 Physica B301 196

27. Dremoa R V, Koblyuk N, Mudryk Y, Romak L and Sechovsk V 2001 J. Alloys Compd. 317-318 293

28. Varma C M 1976 Rev. Mod. Phys. 48219

29. Peter S C, Malliakas C D, Nakotte H, Kothapilli K, Rayaprol S, Schultz A J and Kanatzidis M G 2012 J. Solid State Chem. 187200

30. Maple M B, Seaman C L, Gajewski D A, Dalichaouch Y, Barbetta V B, Andrade M C D, Mook H A, Lukefahr H G, Bernal O O and Maclaughlin D E 1994 J. Low Temp. Phys. 951 